\title{
AiMT
}

Advances in Military Technology

Vol. 15, No. 1, 2020, pp. 97-114

ISSN 1802-2308, eISSN 2533-4123

DOI 10.3849/aimt.01350

\section{Autonomous Combat-Support Vehicles in Urban Operations: Tactical and Technical Determinants}

\author{
W. Bużantowicz and P. Turek* \\ Military University of Technology, Warsaw, Poland
}

\begin{abstract}
The manuscript was received on 3 September 2019 and was accepted after revision for publication as technical information on 2 March 2020.
\end{abstract}

\begin{abstract}
:
The idea of using unmanned platforms for combat tasks is progressing. The analysis of contemporary armed conflicts indicates that in the future, military operations will be largely carried out in urbanized areas. The article outlines the tactical conditions determining the operation of unmanned ground platforms on the urbanized battlefield and formulates tactical and technical requirements to be met by an autonomous combatsupport vehicle (ACSV) designed to cooperate with infantry subunits in contemporary and future military operations.
\end{abstract}

\section{Keywords:}

autonomous vehicle, combat support, future military operations, urban tactics

\section{Introduction}

Conflicts in the former Yugoslavia, Chechnya, Afghanistan, Iraq and Syria indicate that in the future, military operations will be largely carried out in urbanized areas [17]. The urban environment creates a wide range of possibilities for conducting operations with infantry subunits, which in these conditions can conduct effective defense. In particular, the appropriate selection of tactical options, skillful command and efficient use of the combat environment's advantages allow the stronger opponent to suffer high losses.

Tactics (as opposed to strategy) are strongly connected and dependent on organizational and technical changes taking place in the armed forces. The decisive influence on the combat model of land forces is currently being made by the electronization and automation of armed struggle and the widespread introduction of new generation combat equipment to land forces, including battlefield robots and drones, precision weapons, network-centric command and communication systems, and other means of

\footnotetext{
* Corresponding author: Faculty of Mechatronics and Aerospace, Military University of Technology, Gen. S. Kaliskiego 2 Str., 00-908 Warsaw, Poland. Phone: +48 261839 452, E-mail: piotr.turek@wat.edu.pl
} 
electronic warfare. This is causing a gradual transformation of independent land operations into combined (i.e. fire-electronic or land-air-cybernetic known also as collaborative combat) operations, which should be considered the most important transformations in tactics of land forces in the $21^{\text {st }}$ century.

Experiences from battles show that in built-up areas, one of the basic forms of tactical operations of the infantry subunit during defense is an ambush, effectively disorganizing the opponent's actions and weakening its combat potential before reaching the main line of defense of its own forces [8]. The basis of these activities is the fact that the weaker side of the conflict sees the possibility of victory by surprising the opponent and bleeding him in street fights. It should be assumed that the ambush will continue to play a significant role in built-up activities as an effective form of combat.

The basic kind is a point ambush, usually carried out by an infantry platoon although there are opportunities for strikes like "strike and jump back" performed by separate teams. Urban areas also allow implementing area ambushes where platoons or sections organize separated in space but synchronized in time and mission objectives point ambushes $[8,9]$. In such situations, the assurance of their own forces carrying out the attack, the required fire support and situational awareness and minimizing losses among their own troops, are of particular importance. Specialized autonomous combat-support vehicles (ACSV) may be used for such tasks.

The future development direction of ACSVs is formulated, among others, in [10]. Included are guidelines for autonomous and semi-automated systems, including platforms accompanying infantry subunits. This document is one of the most up-to-date ones describing the issues of robotic battlefield support systems, especially since some of the concepts included are planned for implementation from 2020 onwards.

This document defines five milestones, the achievement of which determines an advantage on the future battlefield [10]: a) increasing situational awareness at lower levels of command; b) reducing the warfighters' physical and cognitive workloads; c) sustaining the force with improved distribution, throughput and efficiency; d) facilitating movement and maneuver; and e) force protection. It is significant that the issues related to providing access to information (situational awareness) at the lower levels of command were mentioned first, pushing other important issues into the background. As one of the three main challenges for the army in the future, the capabilities of combat subunits conducting activities in the urban environment are noted.

In analyzing contemporary armed conflicts, the increase of the contribution and significance of operations carried out in urbanized areas is noticeable. This is a consequence of, among others, changes in the manner of implementation of combat operations in areas of operational interest, which are currently characterized by dynamics and localness of operations and are aimed at taking control over key areas and infrastructure elements, using units that are mobile, efficiently commanded, heavily saturated with modern combat, recognition and communication means, and of lower organizational level (i.e. platoon, company, battalion). It should therefore be assumed that subunits, performing combat tasks on the modern battlefield, will increasingly operate in urban and suburban areas as a consequence of the fact that nowadays citizens are converging to megalopolis to find jobs and services. It is even said that: "It is not beyond reason to imagine that eventually urban warfare will become synonymous with warfare, a norm rather than an exception." [11].

In this context, the provision of support to subunits that perform combat tasks in urban areas is of particular importance. This necessity has already been noticed, and the manifestation of the reaction to the changing conditions of the modern battlefield 
is the emerging concepts of advanced means of fighting drones and combat robots dedicated to supporting the actions of subunits, primarily in urban areas.

The article presents the results of an analysis of tactical and technical requirements for an ACSV designed to cooperate with infantry subunits under contemporary and future requirements posed by the urbanized battlefield. The conclusions in the work became the starting point for formulating tactical and technical requirements for the newly designed PERUN platform intended for the Polish Armed Forces.

\section{Operations in Urban Areas as a Determinant of the Direction of Devel- opment of ACSVs}

\subsection{Properties of Urbanized Area}

By definition, more than $50 \%$ of an urban area is covered with cities, urban-type settlements, industrial facilities and infrastructure (rest of the region includes terrain not processed by humans). Built-up areas and associated human clusters create specific conditions for fighting, essentially limiting maneuvering and range of fire. An important role in combat activities is played by the character of buildings, defined by the density and type of buildings, their construction and the population density that is inherent to this area. Differences arising from the structure, type, density and size of the buildings, the number of inhabitants and the functions carried out in the political, economic and cultural spheres are the hallmarks of an urban area and at the same time indicators of its classification.

The internal structure of the city is formed by the character of the buildings and the network of streets, transport nodes, parks, gardens, sports stadiums, squares and undeveloped areas. The type of building has a significant impact on the way the activities are carried out. It will depend on the number and type of troops to be used, the manner of supporting and securing the fighting units, and providing the civilian population with basic livelihoods. There are a) compact buildings (buildings that are very close to each other, almost without spaces between them); b) dense development (small gaps between buildings); c) loose housing (buildings that are at a certain distance from each other); and d) dispersed buildings (there are considerable distances between buildings). The density of buildings depends to a large extent on the size of the city. In medium-sized cities, the density of development is $20-30 \%$, and in large cities, it can be $30 \%$ to $50 \%$ or more.

A compact structure is most often found in city centers. Most medium-sized and large cities in Europe have a characteristic spatial layout. The central part is usually the so-called "Old Town", which was formed in the early Middle Ages. In general, it can be assumed that present-day centers consist of multi-story buildings, the amount of which is determined by the size of the city. It is usually made of durable buildings with thick walls made of brick or concrete. The construction of this part of the city is compact, while the streets are characterized by low capacity. In quarters with built-up compact buildings, combat vehicles can only move along the streets. Usually, they are narrow and winding, which means that in areas of intense fighting, there may be a situation when the march of military vehicle columns will not be possible without the support of engineering subunits.

Loose buildings are characteristic of new cities, towns, settlements and peripheral districts. They are characterized by wide through streets and a large number of squares, and the built-up area is clearly divided into separate quarters (districts). On 
the outskirts of city centers, housing estates are often composed of multi-story and multi-dwelling residential buildings, standing singly or grouped in housing estates. The peripheries consist of low buildings with single- or several-family housing and a higher density of tree stands. On the outskirts of cities, there are usually industrial regions (combined heat and power plants, power plants, sewage treatment plants, factories) and communication zones (railway and road junctions, airports). Industrial buildings are characterized by irregularity, a large number of halls, garages, and hangars, making it easier to conceal and move forces.

\subsection{Outline of the Nature of Activities in the Urbanized Area}

All components of the city have a significant impact on the preparation and conduct of combat operations [8, 9, 11-14]. In particular, they a) limit the field of fire and observation; b) create favorable conditions for insuring concealing troops and equipment, which increases the difficulty in assessing forces; c) reduce the possibilities of maneuvering, in particular of armored, mechanized and motorized units; d) increase the possibility of penetration and bypassing by the armies of both sides, thereby increasing the element of surprise in actions; e) enforce combat in areas with limited opportunities to overcome them by military equipment, which strongly affects the use of tanks, infantry fighting vehicles and wheeled armored personnel carriers in direct contact with the opponent; f) enforce fighting in direct contact, which increases the vulnerability of vehicles to engagement from close range due to limited room for maneuver; g) cause high consumption of ammunition and combat means; h) create difficulties in command, control and communications (command must be decentralized); and i) limit the activities of troops due to the presence of civilians and objects protected by international law.

A characteristic feature of combat waged in urban areas is the presence of civilians. Therefore, particular attention should be paid to the appropriate selection of targets and means of engagement. The targets should be accurately identified, and their engagement should be carried out with the help of precise weapon delivery. The use of weapons with high firepower and low accuracy should be largely limited and is justified only in exceptional cases in which the consequences of such action regarding the civilian population are considered in detail.

Another characteristic feature of conducting operations in the city, which does not occur in other combat environments, is multidimensionality. Operating in the urbanized area is associated with the need to fight on three levels: at the street level, underground (in basements, sewage systems and underground passages and tunnels) and above ground (in buildings and on rooftops).

Street level is the area of direct combat. It allows the defending side to conduct effective fire in the direction of attackers in many ways. For example, building windows can be turned into fire posts, which provide a large angle of fire and allow an effective attack of the opponent. In addition, shooting holes are created by using breaks in the walls that have resulted from explosions. At street level, forces and fire support means are deployed. Squares, parking lots and parks are transformed into artillery posts (for cannons or howitzers). Due to the high trajectory of the projectile's flight, as well as the size, ease of transport and concealment, mortars are widely used in urban areas. Even inaccurate artillery fire can create confusion in the ranks of the opponent and facilitate the task of the forces in direct contact. 
Underground facilities are the most complicated element of the city's architecture from a tactical point of view. The network of underground facilities, their structures, layouts, and locations depend on the character of the urbanized area and are very diverse. In larger cities, underground infrastructure includes garages, tunnels, underground passages, sewers and subway lines. Even in smaller cities, an extensive network of sewers and storm drains allows soldiers to move below street level, which enables single soldiers, and even their groups, to hide and secretly pass through the urbanized area. Attackers can focus the opponent's attention on carrying out activities at street level, while small groups can channel behind the opponent to loot him or force him to engage his forces to fight at two levels. It should be remembered that fighting below street level is limited, mainly due to the small and closed space of operation. Gunshots in such conditions are very noisy, which can lead to hearing loss, and ricocheting projectiles from walls can hurt the unit's own troops because this level is mainly used for the movement of forces and to surprise the enemy (e.g. by going to unexpected places).

During fighting at street level and inside buildings, fighting forces fire from rooftops. Snipers and soldiers equipped with anti-tank grenades and portable anti-aircraft missiles hidden behind chimneys of buildings and other construction elements can effectively eliminate the enemy's forces, armored fighting vehicles (the armor of which is weakest at the top) and air strikes (in particular, helicopters and attack aircraft, which usually operate at low altitudes).

On the other hand, urban areas create favorable conditions for hiding troops, enabling, among others, secretive movement of forces in the course of conducting operations at all levels, which can be further strengthened by the skillful use of camouflage, decoys, thermal curtains or artificial smoke. Infrastructure elements in turn create innumerable dead and covered fields, which provide unlimited possibilities for hiding from observation (optical, thermal or radar systems), as well as indirect and direct fire.

Observation in built-up areas is greatly limited. In practice, observation is possible only along major roads and in other cases it is limited by the spatial arrangement of buildings. The observation sector is narrow, making it necessary to increase the number of observation posts, which should be placed on the roofs of buildings located along roads to ensure maximum effectiveness. The use of technical means of observation (e.g. unmanned aerial vehicles) will increase efficiency, but it will mainly relate to the line of communication routes. It should be noted that observation will often be carried out under conditions of strong smoke and dust.

The ability to conduct fire is limited by the rules that limit observation. Generally speaking, in the urbanized area, the distance between fighting subunits decreases. Direct fire can be carried out along or across roads (between buildings). Small distances between buildings limit the possibility of using the main weaponry of combat vehicles. Due to the widespread dead and hidden areas, the possibility of indirect fire (e.g. using howitzers or mortars) is also limited.

In analyzing the urban area coverage due to terrain obstacles, it can be generally stated that the urban area is in itself an obstacle. Natural obstacles in the area include rivers, lakes, canals, dikes, parks or elevations. In cities, as a rule, the maximum freedom of traffic is sought, so in case when city is unprepared for the defense (by the military), artificial obstacles in principle do not occur. A significant limitation may be the width of streets in the areas of operations, which will determine the possibilities of moving subunits. At the initial stage of combat operations, artificial obstacles will 
probably only result from preparatory work. These obstacles will mainly focus on roads and other communication lines, and their goal will be to obstruct traffic and maneuvers of opponent forces. Over time, warfare will lead to collapses, rubble and barricades, the removal of which will require machinery.

Special conditions for conducting urbanized operations in relationship to the traditionally understood battlefield are presented in a synthetic form in Tab. 1. They allow indicating the necessary construction solutions of ACSV designed to interact with light infantry subunits during operations carried out in urbanized areas.

Tab. 1 Indicative, generalized values of urban action parameters important due to the formulation of tactical and technical requirements for ACSV

\begin{tabular}{|c|l|l|l|}
\hline No. & \multicolumn{1}{|c|}{ Parameter } & \multicolumn{1}{c|}{ Urbanized area } & \multicolumn{1}{c|}{ Classical battlefield } \\
\hline 1. & $\begin{array}{l}\text { formation in which } \\
\text { ACSV operates }\end{array}$ & $\begin{array}{l}\text { in tandem or in a group } \\
\text { of several vehicles }\end{array}$ & $\begin{array}{l}\text { large formations of } \\
\text { troops }\end{array}$ \\
\hline 2. & $\begin{array}{l}\text { targets attacked by } \\
\text { the ACSV }\end{array}$ & $\begin{array}{l}\text { single soldiers, fortified } \\
\text { points, hiding places }\end{array}$ & $\begin{array}{l}\text { other vehicles, } \\
\text { including armored ones }\end{array}$ \\
\hline 3. & $\begin{array}{l}\text { the type of weapon } \\
\text { with which the ACSV } \\
\text { is attacked }\end{array}$ & $\begin{array}{l}\text { sub-caliber and cumula- } \\
\text { tive ammunition, } \\
\text { improvised explosive } \\
\text { devices (IED), explo- } \\
\text { sively formed } \\
\text { penetrators (EFP), vehi- } \\
\text { cle-based IED (VBIED) }\end{array}$ & $\begin{array}{l}\text { sub-caliber and cumu- } \\
\text { lative ammunition }\end{array}$ \\
\hline 4. & $\begin{array}{l}\text { the expected (proba- } \\
\text { ble) direction of } \\
\text { the opponent's attack }\end{array}$ & $\begin{array}{l}\text { all directions are equal- } \\
\text { ly likely }\end{array}$ & front \\
\hline 5. & $\begin{array}{l}\text { distance of observation } \\
\text { and fire }\end{array}$ & $\begin{array}{l}\text { from a few to several } \\
\text { hundred meters }\end{array}$ & $\begin{array}{l}\text { from a few hundred } \\
\text { meters to about } \\
1-2 \mathrm{kilometers}\end{array}$ \\
\hline 6. & $\begin{array}{l}\text { angles of fire in the } \\
\text { elevation }\end{array}$ & from $-15^{\circ}$ to $+75^{\circ}$ & from $-5^{\circ}$ to $+15^{\circ}$ \\
\hline 7. & turret rotational speed & desirable at least $120^{\circ} / \mathrm{s}$ & from $30^{\circ} / \mathrm{s}$ to $60^{\circ} / \mathrm{s}$ \\
\hline
\end{tabular}

\subsection{Summary}

Activities in urbanized areas are among the most difficult military operations, both at the tactical and operational levels. Fighting in urban areas is difficult due to the terrain's properties. The field of view is limited by buildings, ruins and ad-hoc fortifications, which provide cover and protection for the defenders. Operations are hindered by the presence of sharpshooters and booby-traps. The tactical limitations imposed by the fighting area and the need to effectively use the forces and combat resources create the need to provide the fighting units with appropriate support, both fire and information, in the field of broadly understood situational awareness. These analyses point to the need to undertake equipping the armed forces with unmanned battlefield platforms designed to support light infantry operations in mass zones of urban destruction of conventional weapons. 


\section{Requirements for an ACSV in Terms of Tactical and Technical Conditions}

\subsection{Initial Assumptions}

It is assumed that the main purpose of the planned ACSV will be a) accompanying a light infantry subunit or mechanized infantry subunits to provide fire and information support (by increasing situational awareness on the battlefield) during battles in the urbanized area; and b) acting to protect and defend troops in quasi-urbanized areas (bases and facilities for military use, fortified security zones, formations deployed in positions with permanent engineering build-up, etc.) or in the field on field-type positions. The considerations refer to the tasks listed above. The equipment and tactical and technical parameters of the analyzed platform do not exclude the possibility of using it for other tasks, but this is treated as an option and will not be subject to a broader analysis.

It is natural that ACSV should be a part of greater support system which is consistent in tactical and logistical matter. The system should provide logistic support for the subunit equipped with the platform under consideration, especially with the spare parts, petroleum, oil and lubricants as well as field repairs. The draft of proposed system is presented in Section 4 of the work.

In the construction of ACSV, one should take into account the elements of the "extreme modularity" postulate $[15,16]$, which means redundancy of key components, power supply systems and information exchange channels enabling a) relatively quick repairs in field workshop conditions with the use of spare parts kits; and b) assembly of specialized equipment modules depending on the planned mission. It is necessary to pay attention to the necessity of maintaining the balance in the cost/effect relationship. It is pointless to design an ACSV intended for operations in all tactical and terrain conditions, accompanying each type of armed forces. Divergent (and often mutually contradictory) requirements as to tactical and combat capabilities, as well as the very high cost of specialized equipment, make considering such versatile construction a mistake for utilitarian and economic reasons.

\subsection{Base Chassis}

The chassis together with the suspension should provide an appropriate level of off-road capability and mobility that allows the ACSV to move at a speed of at least $20 \mathrm{~km} / \mathrm{h}$ on paved roads and at least $5 \mathrm{~km} / \mathrm{h}$ on difficult terrain (i.e., with the average rate of light infantry subunit movement). Assumed velocity range allows maintaining movement rate of dismounted units as well as swift withdrawal in case of the danger. On the other hand, such velocity range greatly simplifies the platform drive, mostly gear construction. In an urbanized environment, it is not assumed to be able to overcome boggy or marshy terrain in which unit pressure would be of key importance. In addition, due to the small weight of the platform (compared to classic combat vehicles), it is possible to abandon the idea of the crawler drive. Adequate mobility in urbanized areas can be provided by the wheeled chassis, with proper selection of chassis parameters, especially with regard to suspension. The chassis should be able to overcome terrain with high density and various obstacles (e.g. rubble, landslides, thresholds) and to move the vehicle with longitudinal and lateral inclination. Due to the reliability and maneuvering requirements in a limited urban space, it is advisable to use a wheeled system with three torsion axles and off-road tires resistant to overshooting. 
Considering the probable high losses among combat platforms participating in battles in a particularly difficult and specific environment, one should strive to obtain constructions built on the basis of typical (standardized) elements, possibly even using systems produced for the needs of the civilian market. An example might be, for example, a chassis and platform suspension based on modified subassemblies of civil, quad all-terrain vehicles (ATVs). Such a chassis is characterized by the required level of mobility with simultaneous provision of adequate load capacity and space to accommodate executive systems, fuel tanks, power supply elements, and other on-board equipment.

The power supply system should a) ensure uninterrupted interaction of all platform modules in the assumed continuous operation time (up to 72 hours); and b) supply at least $1 \mathrm{~kW}$ of power to enable charging of batteries and devices on the individual equipment of soldiers of the subunit. Due to the assumption that subunit is combat-tasked with operation in urban terrain, it could be cut off from their own troops, which enforce operating individually. In that circumstances, the intended value of external power supply should provide fulfillment of existence needs (e.g. water or air heaters require relatively high value of power). The ACSV should be equipped with marker lights and dimmer modules of basic lighting.

\subsection{Armament and Special Equipment}

The main task of the ACSV will be to support light infantry at the street level. This makes it necessary to ensure the appropriate penetration of construction materials, which can provide hiding places for the opponent. For instance, $7.62 \mathrm{~mm}$ rifles can only penetrate lightweight shields such as wooden walls and doors and drywall. External elevations of medium-rise urban buildings are usually constructed of brick or reinforced concrete, so the use of remote-controlled armament module with $12.7 \mathrm{~mm}$ machine gun and automatic $40 \mathrm{~mm}$ grenade launcher is postulated.

The purposefulness of using a $12.7 \mathrm{~mm}$ machine gun confirms the theoretical analysis of the problem of penetrating construction materials. To compare the two calibers, a standard ogival shape of the projectiles was considered. The analysis made on the basis of $[17,18]$ refers to the penetration of $7.62 \times 51 \mathrm{~mm}$ and $12.7 \times 99 \mathrm{~mm}$ projectiles. With the assumption of non-deformability during penetration, a projectile with a mass $m$ and a diameter $2 a$, striking an obstacle with the velocity $V_{0}$, in the first phase breaks a concrete crater similar in shape to the cone from the obstacle. The depth of this crater is twice the caliber of a projectile hitting an obstacle, which is confirmed by the experiments and simulations contained in [18]. Then the projectile moves through a tunnel with a diameter similar to that of the projectile until the final depth of penetration is obtained.

The final penetration depth of the projectile in the concrete obstacle can be described as [17]

$$
p=\frac{m}{2 \pi a^{2} \rho N} \ln \left(1+\frac{N \rho V_{1}^{2}}{S f}\right)+4 a, \quad p>4 a
$$

The speed $V_{1}$ of the projectile entering the tunnel is given by

$$
V_{1}=\sqrt{\frac{m V_{0}^{2}-4 \pi a^{3} S f}{m+4 \pi a^{3} N \rho}}
$$


where $f$ is the strength, $\varrho$ is the density, and $S$ is the construction constant of the obstacle. In this case, $f=15 \mathrm{MPa}, \varrho=2300 \mathrm{~kg} / \mathrm{m}^{3}$. Parameter $S=53$ for C15 concrete with low compressive strength, used in civil constructions, was determined based on the experimental results presented in [19]. Dimensionless variable $N$ is the construction constant of the shape of the projectile's nose described by the formula

$$
N=\frac{4 r a-a^{2}}{6 r^{2}}
$$

where $r$ is the ogival radius.

The following values were adopted for calculations: for a caliber $7.62 \mathrm{~mm}-$ $m=10 \mathrm{~g}, 2 a=7.62 \mathrm{~mm}$, and for a caliber $12.7 \mathrm{~mm}-m=50 \mathrm{~g}, 2 a=12.7 \mathrm{~mm}$. The obtained results for $\mathrm{C} 15$ concrete (Fig. 1) confirm the rationality of using a $12.7 \mathrm{~mm}$ machine gun as the main weapon system for a remote-controlled armament module.

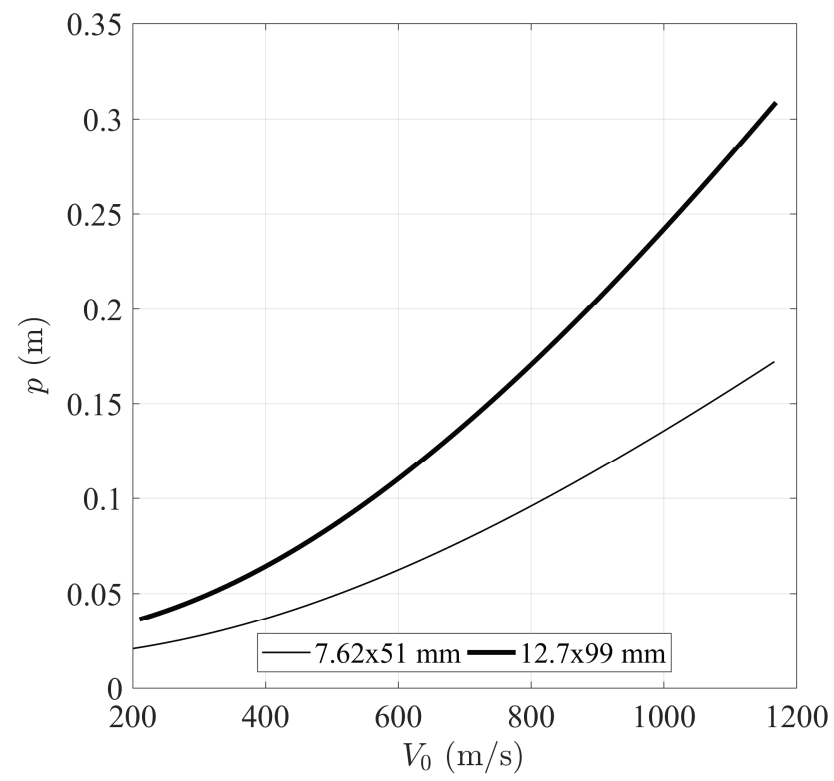

Fig. 1 Penetration of $12.7 \mathrm{~mm}$ and $7.62 \mathrm{~mm}$ projectiles for concrete obstacle

The need to equip the ACSV with an automatic grenade launcher results from the analysis of contemporary armed conflicts, including the current experience of NATO missions in Iraq and Afghanistan [1-7, 20-23]. The usefulness of such a weapon during battles conducted in the urbanized area was also noted by the armed forces of the United States and the Russian Federation. The U.S. Department of Defense ordered in August 2014 (contract no. H92222-14-D-0008) Swedish MT756 ammunition with a tandem warhead to fight in built-up areas and to fight soldiers hidden behind obstacles or in buildings. In turn, Russian units in the early 1990s used grenade launchers for fighting in cities (see, e.g. KPB GM-93/94), characterized by minimum distance of safe use equal to 5 meters (using thermobaric ammunition).

A grenade launcher installed on an ACSV should be an automatic weapon, constructionally adapted for shooting classic ammunition (fragmentation grenades) and special ones (air-fuel, illuminating, flash, smoke, and tear-gas grenades) and the possi- 
bility of the operator choosing the type of ammunition. This configuration allows it to be used to fight enemy vehicles and unmanned platforms and as a support weapon, intended, among others, to destroy strengthened points of resistance, obstacles, and enemy troops, lay down smokescreens or illuminate the battlefield. The grenade launcher provides direct support to fight off opponents' attacks, destroys fighting positions located a few hundred meters away (when throwing a hand grenade at such positions is impossible) and quickly covers with fire a few hundred square meters of terrain.

Consider equipping the platform with systems for automatic detection of chemical, biological, radiological and nuclear (CBRN) contamination, an acoustic system for the detection and location of small arms, and a reflector (searchlight) on the remote-controlled armament module.

Sensoric instrumentation should be selected to ensure the possibility of conducting omni-directional observation and control execution in day and night conditions and in conditions of significant smoke and dust. The observation and sighting devices should enable detecting, recognizing and identifying targets in accordance with NATO standards [24-25]. An interesting option can be to equip the ACSV with passive defense system comprising laser warning receiver module for detection, analysis and location of laser emissions from guidance systems and range finders.

\subsection{Network Centricity and Situational Awareness}

A characteristic feature of the technical development of fighting means is the constant striving to gain advantage over the opponent. Along with the development of technology, in particular in the field of communications and teleinformatics, the idea of conducting combat operations is evolving, gaining, with the beginning of the $21^{\text {st }}$ century, a new, modern dimension. Distinctions of this multidimensionality are the ability to effectively neutralize a wide range of combat agents of the opponent (due to task specialization of individual components of the system) and network centricity.

The essence of network-centric activities is the use of a fast and efficient information exchange system to gain an advantage over the opponent. The aim of these activities is therefore to organize the process of collecting, processing, selecting and distributing information, which ensures the availability of the necessary data in the right place and time, whereby the spatial distribution of information sources is irrelevant. In the case of the ACSV, data on the enemy can be provided by sensors located on the vehicle (e.g. optical, thermal or radar systems, acoustic shooter location systems, CBRN sensors), data from other unmanned (land and air) platforms operating in the area of interest, higher-level command and communication systems, satellite systems and many more. What is important is that the information available to the commander is accumulated in real time on the basis of partial data collected as a result of activities carried out in parallel by many elements in the system. The characteristic feature of operating in a "digital" environment is data stream redundancy (understood as multiple channel transmission of the same data in the communication system) and the need to process information in real time.

The peculiarity of ACSV should therefore be functionalities not found in other weapon systems currently used in the armed forces. In particular, they should concentrate on providing broadly understood support aimed at increasing situational awareness of the fighting formation and thus should provide modern tools for effective observation, recognition and support of the decision-making process in national and 
allied context [21, 22]. Therefore, the data processing modules, communications and software of the unmanned platform in the area of increasing situational awareness should be oriented toward a) selection (decimation) of information and presenting it in an accessible way through the user interface of the system; b) supporting the commander's (operator's) decision-making; c) secure transfer (distribution) of data and information support to the platoon commander (company) for which the section equipped with ACSV operates; d) the possibility of cooperating with external command and communication systems, including data exchange with other unmanned platforms, including within the framework of "swarm" formation [26] and with unmanned aerial vehicles conducting reconnaissance operations for the operating subunit; and e) the ability to identify targets for flying combat drones (loitering munitions systems).

\subsection{Communication and Control}

Taking into account the postulates formulated in Section 3.4, communication in the system should be based on the network-centric model, consistent with the technical architecture of $\mathrm{C} 3$ systems and based on the exchange of available services and the use of standard solutions to the maximum extent using commercial solutions (COTS commercial off-the-shelf). The basic variant of communication with the system could be, for example, wireless communications based on IP technology that will allow full use of the advantages of autonomous operation, allow scaling of the network-centric system and does not impose restrictions on the range of maneuvers performed during these operations. Due to the need to use wireless communications in the device, it is necessary to ensure an appropriate level of resistance of the target platform control system to external electromagnetic signals, both artificial and intentional. For security reasons and to increase the resistance of the communications system to interference, it is desirable to use redundant control channels in different frequency bands. The key aspect of system security is the system's robustness for its remote acquisition, which should be achieved through the use of software and hardware cryptographic solutions. The trend currently developed in cryptography is Secure Communications Interoperability Protocols (SCIP) technology, which defines the requirements for technical specifications of cryptographic devices for use in secure communication systems, as well as it describes the security of the application layer (according to the OSI model). The standard nowadays is the use of transmission encryption AES256. Data communication technologies in the field of direct line-of-sight (LOS) and tactical data links used on the battlefield should be used to exchange data in the system. The tactical links currently use slot allocation technologies for communication with a single TDMA network user and CDMA spectrum scattering.

Action on the modern battlefield forces the necessity of sharing information by many devices used by the army. For many years, there has been a trend of increasing the number of communicating devices operating on one or more networks. Additionally, if communication takes place via electromagnetic waves (wirelessly), these devices must use the allocated transmission bands. One of the most important difficulties is the necessity of many devices sharing common transmission bands. Frequency jumps in the CDMA bandwidth range cannot be accidental, and radio devices must work according to a synchronized scheme. This approach allows sending information by several users using the same communication channel (frequency band) after agreeing upon transmission details. The radios used in the system should be broadband digital 
IP radios with the possibility of programming their work in a selected frequency band while also programming the waveform of transmitted signals by applied modulation techniques.

The complex issue is the transmission of image data in near real time via wireless links. Standard tactical links have a bandwidth of several Mb/s. Image data due to their specificity require significantly higher bandwidth connections. Due to the necessity of remote control based on the image as well as the detection and recognition of targets before they are engaged (neutralized), an appropriate quality of the transmitted imaging is necessary. It is therefore necessary to set up an additional data link for image transmission. This channel should enable image transfer to both system operators and the C3 supervisor system. Due to the sensitivity of the communications elements in the event the platform is taken over by the opponent, a solution that enables permanent remote destruction of communications elements should be implemented. It must be highlighted that autonomous self-destruction of whole vehicle is connected with high level of risk for own troops cooperating with the platform in the battlefield. Non-explosive, remote solution of destructing crucial electronic components (such as communication modules) responsible for control or consisting sensitive knowledge about its operation should prevent opponents from the usage of ACSV.

During the execution of combat tasks in an urbanized area, ACSV operations should be carried out in remote (non-autonomous) control mode through portable operator consoles. Due to the high dynamics and specific character of activities carried out in the urbanized environment, it is necessary to provide two unified operator consoles to control a single platform: a) console working in "master" mode, responsible for handling payload (armament, specialized equipment); and b) console working in "slave" mode, responsible for controlling the movement of the platform itself. It should also be possible for a single portable console to control both equipment and platform in case of emergency. Because during combat in an urbanized area, the distance between the fighting parties is shortened, the means of communications provided by the portable operator consoles should ensure the control of the vehicle's armament and movement over a distance of up to $1 \mathrm{~km}$. In urban terrain, because of obstacles and broken line of sights, effective operational distance is in practice limited for distances up to tens of meters. However, ACSV may be planned as an advance guard forward security or recon element, which implies the necessity of distant operating (e.g. securing a bridge or advancing along the street). Assumed communication range is sufficient for these applications.

As it was mentioned above, the concept of an operational use of ACSV in formation will be described briefly in Section 4. At this moment, it is reasonable to assume that the platform and its operators are protected by the soldiers from the subunit for which ACSV operates.

During the fulfillment of the tasks of defending and securing one's own troops (facilities) in a stationary mode (based on a stationary operator's station), combat work should normally be carried out by a section composed of two operators, the first of which supports the armament control console and the second of which supports the vehicle control console. Based on the general conditions for operations of military units, the means of communications located on the stationary equipment should ensure undisturbed control of the vehicle's equipment and movement within a radius of 5-7 km, which should be sufficient for effective securing approaches for protected forces or military bases where ACSVs patrol along the perimeter. In this mode of operation, ACSV can be allowed to move autonomously-independently after 
a pre-planned or real-time route [27] under the supervision of the operator. In the event of the loss of communication, the option of automatically returning the platform to the starting point should be considered, although the potential danger of such a solution should be taken into account (e.g. a vehicle intercepted by the opponent's diversion team can be used as a "suicide" platform to deliver an explosive charge into the protected area).

\subsection{Transport Requirements}

With regard to modern requirements in the field of transport technology of goods by military road transport in the areas of operations and in tactical zones, attention should be paid to the pursuit (wherever possible) of their unification. It consists of the transport of cargoes placed in the so-called loading units, i.e. in standard containers, on pallets or in packages. Twenty-foot transport containers are commonly used in the logistics subsystems of the leading armies of NATO countries. Based on the dimensions of this container, various types of multifunctional containers are created, such as repair workshops, field social elements, elements of communication systems, medical treatment rooms and units for transporting soldiers and specialist equipment. An extremely important structural feature of the container system is that its dimensions, volume and weight are fully compatible between its components and commonly used handling devices, sizes of ship-loading slots, supply vessels and cargo aircraft. This dependence is also maintained on railway platforms, fleets of general-purpose vehicles and individual groups of medium and high mobility vehicles used in military transport systems. Considering this, it seems reasonable to secure the operation of the ACSV based on standardized containers, transported by typical transport means, e.g. trucks with hook lift (arm roll) systems. This fact which has consequences for all logistic support system and organization of the unit equipped with ACSV was used as one of the key requirements for the conception of operational usage of the system (described in Section 4).

It should be possible to tow the platform with a rigid tow-rod at speed of up to $60 \mathrm{~km} / \mathrm{h}$ on paved surfaces to provide an alternative way of delivering the ACSV to the operational area or for technical rescue and evacuation purposes. Optionally, the ACSV may be equipped with handles, enabling them to be suspended under a transport helicopter.

\subsection{Safety Aspects}

From the point of view of tactical conditions, it is particularly important when planning activities in urbanized areas to take into account the presence of civilians on the battlefield. The reduction of the destructive impact of operations on the civilian population is a special task of the troops. This is not only a common law, but also a requirement regulated by international law, including Art. 27 of the IV Geneva Convention [28]. In this connection, consideration should be given to equipping the platform with deterrence and non-lethal effectors, such as a deterrent siren or tear-gas grenades, as an extra equipment for dealing with non-combatants during peace-keeping and peace-enforcement operations.

A particularly delicate issue is equipping autonomous systems with elements of weapons. For reasons of security, the ACSV must not have any autonomy in making decisions about the use of weapon systems and measures of non-lethal impact. The security aspects related to operations realized by unmanned ground platforms should 
be the subject of detailed considerations in specialized dissertations and will not be discussed here in detail.

\section{Outline of the Concept of Operational Use}

An ACSV with a considered (or similar) configuration should ultimately be part of a larger system that allows it to be included in the actions of larger forces. The process of introducing unmanned platforms must take into account existing structures and be consistent in terms of tactics, logistics, transport and personnel.

Under such assumptions, the platoon of ACSVs placed in the structure of the headquarters battalion of the mechanized brigade could be a specialist element, available to the brigade commander, intended to support mechanized subunits in tactical operations in urbanized areas, as well as force protection tasks. Such a platoon would consist of 4-5 teams, each with two sections. Each section would be composed of two operators that support one ACSV. Each team should be equipped with its own support vehicle with a driver. The team's equipment could include a) two ACSVs with a weapon system and required equipment (including one stationary and two sets of mobile operator consoles) and a set of tools and spare parts; b) a standard 20-foot container, adapted for loading and unloading by means of hook lift systems, equipped with two stations for fixing and transporting ACSVs, internal and external communication, power generator, main and combat lighting, filtering system with air conditioner, firefighting measures (powder extinguishers) and first-aid medical devices and a set-up for attaching the aforementioned equipment; and c) support vehiclea high mobility truck, equipped with a 5 -seat cabin, providing ballistic protection and crew safety at level 1 according to STANAG 4569 [29], hook lift system and a set of towing equipment. Such a configuration should ensure effective use of the equipment both in combat conditions and during force protection tasks.

In the first case (Fig. 2), the sections are delivered to the area of activity by means of a) their own support vehicles, b) towed, transported or semi-transported by other allocated means, or c) transported by means of helicopters. It should be noted that the concept of urban areas should provide for the use of at least the whole team (i.e. two ACSVs and four operators).

A general rule is that ACSVs should not operate individually in a built-up areathere should be a minimum of a pair of covering vehicles, see e.g. [13]. During the execution of combat tasks in an urbanized area, the ACSVs' work should be carried out in the remote control mode. In the case of using two portable consoles, all operators are involved in the operation of the equipment-the team (section) leader is responsible for controlling the weapon module and the second operator for steering the vehicle. In the case of working with a single console, the operator, armed with a carbine, ensures the commander controls the ACSV.

In the case of the other, the container placed on the base becomes the point of control from which the supervision over the security of the protected objects and ongoing monitoring of the situation are conducted (Fig. 3). In such a situation, a certain autonomy of the vehicle's movement is allowed, e.g. in following a given patrol route or returning to the driving point, while maintaining a categorical prohibition of unauthorized (autonomous) use of weapons. Container equipment (operator's station with comfortable armchairs, air conditioning, communication means) provides the required comfort and the ability to perform tasks in a two-shift system (assuming the use of only one ACSV in the considered time interval). 


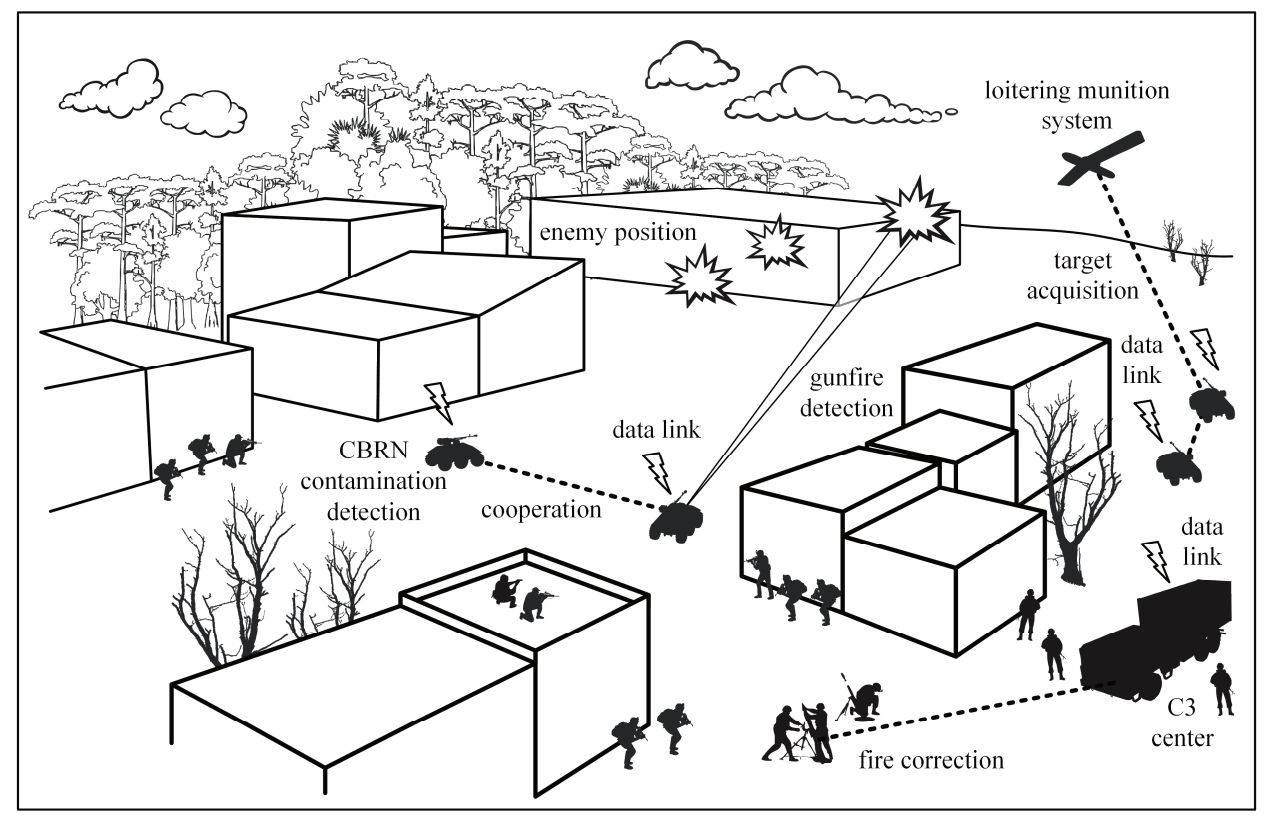

Fig. 2 Vision of using the system in an urban environment

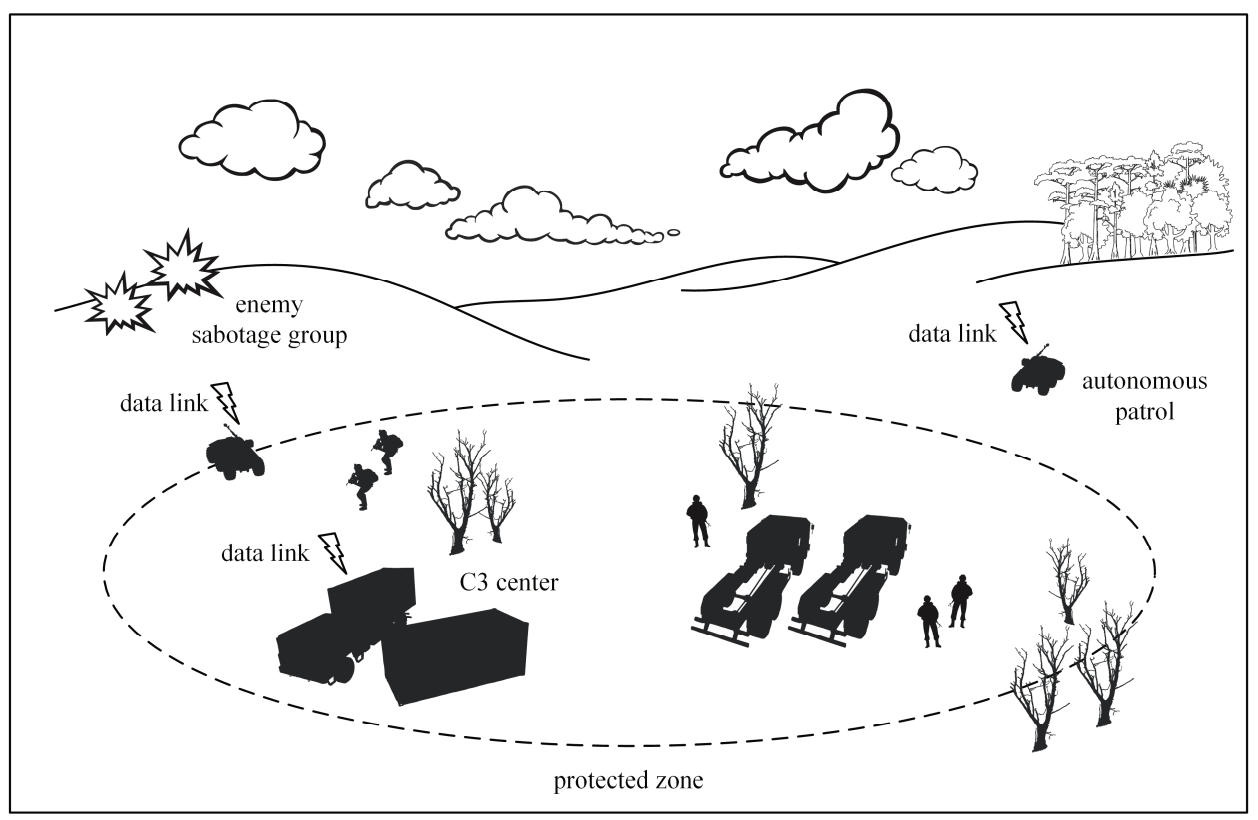

Fig. 3 Vision of using the system to force protection tasks 


\section{Summary and Final Remarks}

The article describes the properties of the urbanized area as the environment for carrying out combat operations and it presents an outline of the tactical conditions determining the operation of autonomous combat-support vehicles on the urbanized battlefield. Attention is paid to the increase in the significance of operations carried out in the urban environment and development trends in the field of unmanned ground platforms.

The concept of the location of the proposed ACSV system in the structure of the mechanized brigade was presented, and the method of its use in operational conditions was outlined. Attention is drawn to the fact that the examples do not exhaust the possible areas of use of ACSVs. Their use for tasks other than those discussed here should be preceded by broader analyses and conclusions from the operation of test platforms under the conditions of a military unit.

In spite of discussions on the modernization of armed forces and the beliefs expressed about the need to deploy autonomous systems to the armed forces, unmanned ground platforms (excluding a certain group of platforms used by specialized subunits) will be a big novelty and a qualitative leap for both soldiers and their commanders. At the same time, it should be emphasized that this leap will mainly concern a change in the way of thinking (of both leaders and operators) and the planning and operating of subunits on the battlefield. It is obvious that it must bring about changes in the personnel structures of military units, which may be difficult to accept due to the habits of the classic organizational structures and the usual methods of solving tactical and operational problems. Therefore, an evolutionary approach should be used, allowing for a smooth transition from the structures and procedures currently in force to structures and procedures that take into account the presence of armed, un-manned platforms on the battlefield, as well as the benefits. This will enable the gathering of experiments, technical development of the proposed combat platform, close adjustment of its tactical and combat capabilities to the needs of the armed forces, creating favorable conditions for the development of tactics for the use of this type of vehicle within mechanized forces and setting the direction of changes in the organization of subunits.

The participation of ACSVs in operations conducted on future battlefields will systematically increase. The platforms themselves are generally characterized by high development potential, which creates the possibility of developing the structure in response to the challenges posed by future threats, as well as changes in the military equipment. The fundamental advantage of implementing these systems to the armed forces will be the intellectual and economic activity of the defense industry and the scientific community associated with military technology.

\section{Acknowledgement}

This work is financed by the National Centre of Research and Development of the Republic of Poland as part of the scientific research program for the defense and security named "Future Technologies for Defense-Young Scientist Contest" (grant no. DOB-2P/02/03/2018). 


\section{References}

[1] ROSENAU, W.G. Every Room Is a New Battle: The Lessons of Modern Urban Warfare. Studies in Conflict and Terrorism, 1997, vol. 20, no. 4, p. 371-394. DOI 10.1080/10576109708436047.

[2] TIMOTHY, L.T. The Caucasus Conflict and Russian Security: The Russian Armed Forces Confront Chechnya III. The Battle for Grozny, 1-26 January 1995. Journal of Slavic Military Studies, 1997, vol. 10, no. 1, p. 50-108. DOI 10.1080/13518049708430276.

[3] MITROKHIN, N. Infiltration, Instruction, Invasion Russia's War in Ukraine. Osteuropa, 2014, vol. 64, no. 8, p. 3-16.

[4] GRAU, L.W. Russian Urban Tactics: Lessons from the Battle for Grozny. Strategic Forum, 1995, vol. 38, p. 1-4.

[5] PILAV, A. Before the War, War, after the War: Urban Imageries for Urban Resilience. International Journal of Disaster Risk Science, 2012, vol. 3, no. 1, p. 23-37. DOI 10.1007/s13753-012-0004-4.

[6] SPEYER, A.L. The Two Sides of Grozny. In Capital Preservation: Preparing for Urban Operations in the $21^{\text {st }}$ Century. In Proceedings of the RAND ArroyoTRADOC-MCWL-OSD Urban Operations Conference. Santa Monica: RAND Corporation, 2001. 638 p. ISBN 0-8330-3008-6.

[7] MAASS, J. Engineers at War. In: Hoffman J. (ed.). Tip of Spear: US Army SmallUnit Action in Iraq 2004-2007. Washington: Military Bookshop, 2009. 214 p. ISBN 978-1-78-039044-4.

[8] URBANEK, M. Irregular (Unconventional) Actions in Urbanized Environment (in Polish). Obronność Zeszyty Naukowe, 2017, vol. 2, no. 22, p. 247-273.

[9] MAKOWIEC, P. Ambush in Built-up Area. Tactical Case Study (in Polish). Zeszyty Naukowe WSOWL, 2010, vol. 1, no. 155, p. 5-15.

[10] Robotic and Autonomous Systems Strategy. Fort Eustis (VA). U.S. Army Training and Doctrine Command [on line]. March 2017. 31 p. [viewed 2019-06-07]. Available from: https://www.tradoc.army.mil/Portals/14/Documents/RAS_Strategy.pdf

[11] BURTON, G. An Urban Operations Training Capability for the Canadian Army. Canadian Army Journal, 2006, vol. 9, no. 1, p. 91-113.

[12] ATTP 3-06.11 (FM 3-06.11). Combined Arms Operations in Urban Environment [on line]. June 2011, 284 p. [viewed 2019-05-12]. Available from: https://www.globalsecurity.org/military//library/policy/army/attp/attp3-06-11.pdf

[13] The Stryker Brigade Combat Team Infantry Battalion Reconnaissance Platoon, FM 3-21.94. US Army and www.survivalebooks.com, 2003. 347 p. ISBN 978-147-823659-7.

[14] HOLOTA, M. and WASZKIELEWICZ, R. Conception of Tank Construction Assigned to Operations in Urban Area (in Polish). Szybkobieżne Pojazdy Gąsienicowe, 2007, vol. 22, no. 1, p. 1-10.

[15] GABROVSEK, S., COLWILL, I. and STIPIDIS, E. Combat Utility Prediction. Defence Technology, 2016, vol. 12, no. 6, p. 446-463. DOI 10.1016/j.dt.2016.10.002. 
[16] HYBERTSON, D.W. Model-Oriented Systems Engineering Science: A Unifying Framework for Traditional and Complex Systems. Boca Raton: Auerbach Publications, 2009. 388 p. ISBN 978-1-42-007251-8.

[17] FREW, D.J., FORRESTAL, M.J. and CARGILE, J.D. The Effect of Concrete Target Diameter on Projectile Deceleration and Penetration Depth. International Journal of Impact Engineering, 2006, vol. 32, no. 10, p. 1584-1594. DOI 10.1016/j.ijimpeng.2005.01.012.

[18] WARREN T.L., FOSSUM A.F. and FREW D.J. Penetration into Low Strength (23 MPa) Concrete: Target Characterization and Simulations. International Journal of Impact Engineering, 2004, vol. 30, no. 5, p. 477-503. DOI 10.1016/S0734743X(03)00092-7.

[19] GACEK J., MARCINIAK B. and WOŹNIAK R. Selected Aspects of Safety for Designs and Use of Garrison Shooting Ranges (in Polish). Issues of Armament Technology, 2015, vol. 133, no. 1, p. 103-133. ISSN 1230-3801.

[20] FM 90-10-1. An Infantryman's Guide to Combat in Built-up Areas [on line]. May 1993. [viewed 2019-05-12]. Available from: https://archive.org/stream/FM90101 AnInfantrymansGuideToCombatInBuiltUpAreas/FM\%2090-101\%20An\%20Infa ntryman's\%20Guide\%20To\%20Combat\%20In\%20Builtup\%20Areas_djvu.txt

[21] FM 34-130. Intelligence Preparation of the Battlefield [on line]. July 1994. 5 p. [viewed 2019-05-09]. Available from: https://images10.newegg.com/UploadFiles ForNewegg/itemintelligence/Stanley/FM34_1301470283299873.pdf

[22] INNOCENTI C.W. Intelligence Analysis for Urban Combat. U.S. [on line]. Leavenworth: School of Advanced Military Studies, 2002. 75 p. [viewed 201906-09]. Available from: https://apps.dtic.mil/dtic/tr/fulltext/u2/a403530.pdf

[23] TC 90-1. Training for Urban Operations [on line]. April 2002. [viewed 2019-0612]. Available from: https://archive.org/stream/TC_901_Training_for_Urban_ Operations/TC_90-1_Training_for_Urban_Operations_djvu.txt

[24] STANAG 4347. Definition of Nominal Static Ranger Performance for Thermal Imaging Systems. NATO, 1995. $14 \mathrm{p}$.

[25] STANAG 4349. Measurement of the Minimum Resolvable Temperature Difference (MRTD) of Thermal Cameras. NATO, 1995. $10 \mathrm{p}$.

[26] ZHENG, Z. and TAN, Y. Research Advance in Swarm Robotics. Defence Technology, 2013, vol. 9, no. 1, p. 18-39. DOI 10.1016/j.dt.2013.03.001.

[27] PATLE, B.K., PADLEY, A., JAGADEESH, A. and PARDI, D.R. Path Planning in Uncertain Environment by Using Firefly Algorithm. Defence Technology, 2018, vol. 14, no. 6, p. 691-701. DOI 10.1016/j.dt.2018.06.004.

[28] Convention (IV) relative to the Protection of Civilian Persons in Time of War [on line]. August 1949. p. 69. [viewed 2019-06-10]. Available from: https://www.un.org/ en/genocideprevention/documents/atrocity-crimes/Doc.33_GC-IV-EN.pdf

[29] STANAG 4569. Protection Levels for Occupants of Armoured Vehicles. NATO, 2014. 8 p. 